\title{
The potential use of the labelled bicarbonate method for estimating energy expenditure in man
}

By M. Elia, N. Fuller and P. Murgatroyd, Dunn Clinical Nutrition Centre, 100 Tennis Court Road, Cambridge CB2 1QL

Two tracer methods have been used to assess energy expenditure in animals and humans: the doubly-labelled-water method (for animals Lifson et al. 1955; for humans Prentice, 1988; Coward, 1988) and the labelled bicarbonate method (for humans present paper; for animals Corbett et al. 1971). Whereas the doubly-labelled-water technique attempts to provide information about the energy expenditure over long periods of time (2-3 weeks in adult human subjects), the bicarbonate method attempts to provide information about shorter periods of time (hours to days). Both techniques assess carbon dioxide production, and therefore it is necessary to relate $\mathrm{CO}_{2}$ production to energy expenditure. These aspects will be discussed separately.

\section{Assessment of $\mathrm{CO}_{2}$ production}

The bicarbonate method is essentially an isotopic-dilution technique involving either a radioactive isotope of carbon $\left({ }^{14} \mathrm{CO}_{2}\right.$, as in the human study described on pp. 250-255) or a stable isotope of $\mathrm{C}\left({ }^{13} \mathrm{CO}_{2}\right)$. When labelled bicarbonate is infused into the body at a known rate, it will mix with and be 'diluted' by endogenous $\mathrm{CO}_{2}$ produced by the tissues of the body, before it is expired in breath. The extent of this 'dilution' (the specific activity of ${ }^{14} \mathrm{CO}_{2}$ or enrichment of ${ }^{13} \mathrm{CO}_{2}$ ) is used to calculate $\mathrm{CO}_{2}$ production. When a constant infusion of labelled bicarbonate is given, $\mathrm{CO}_{2}$ production can be estimated from the mean specific activity in equation 1 (Corbett et al. 1971).

$$
\mathrm{CO}_{2} \text { produced }=\frac{\text { label infused }}{\text { specific activity of } \mathrm{CO}_{2}}
$$

This simple equation assumes that the labelled $\mathrm{CO}_{2}$ (bicarbonate) infused into the body is totally recovered in expired air after mixing in a single pool of $\mathrm{CO}_{2}$ with unlabelled $\mathrm{CO}_{2}$ produced by the tissues of the body (Fig. 1).

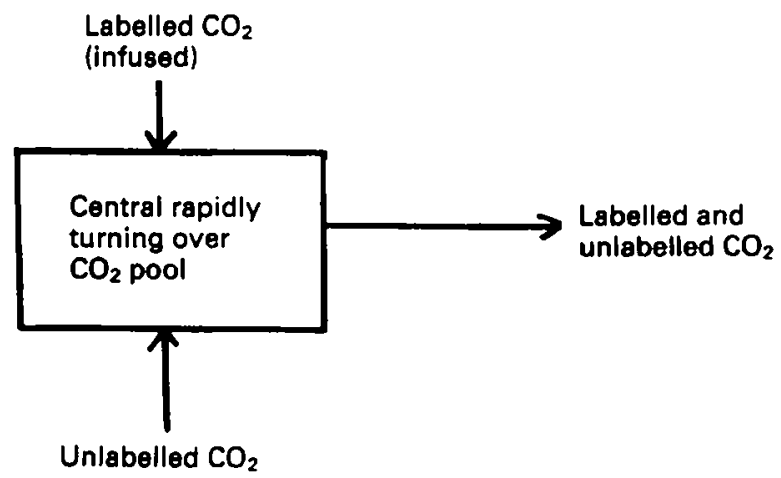

Fig. 1. A simple one-compartment model of carbon dioxide kinetics. 
However, in reality the recovery of $\mathrm{CO}_{2}$ is not complete and the $\mathrm{CO}_{2}$ in the body does not exist in a single pool. In addition the specific activity of $\mathrm{CO}_{2}$ does not remain constant. It oscillates about a mean value because of fluctuations in $\mathrm{CO}_{2}$ production.

Recovery of infused $\mathrm{CO}_{2}$. The recovery of infused bicarbonate in man has generally been reported to range from 80 to $94 \%$ (Issekutz et al. 1968; Winchell et al. 1970; James et al. 1976; Allsop et al. 1978; Clugston \& Garlick, 1983). In one study a recovery of only $51 \%$ was reported (Irving et al. 1983). This incomplete recovery of labelled bicarbonate is largely due to the operation of two processes. The first involves trapping or fixation of $\mathrm{CO}_{2}$ by certain metabolic processes. For example, $\mathrm{CO}_{2}$ is utilized in the formation of urea which may accumulate in body fluids or be excreted in urine

$$
\mathrm{CO}_{2}+\underset{\text { ammonia }}{2 \mathrm{NH}_{3}} \stackrel{\text { urea cycle }}{\mathrm{NH}_{2} \mathrm{CONH}_{2}+\mathrm{H}_{2} \mathrm{O}} \text { urea }
$$

$\mathrm{CO}_{2}$ may also be 'fixed' by other reactions including those catalysed by pyruvate carboxylase (EC 6.4.1.1) and malate dehydrogenase (EC 1.1.1.37; NADP-dependent, also known as 'malic' enzyme)

$$
\begin{aligned}
& \begin{array}{ccc}
\mathrm{COCOOH} & \text { pyruvate carboxylase } \\
\mathrm{CO}_{2}+\underset{\text { pyruvate }}{\mathrm{CH}_{3}} & \begin{array}{l}
\mathrm{COCOOH} \\
1
\end{array} & \begin{array}{l}
\mathrm{CH}_{2} \mathrm{COOH} \\
\text { oxaloacetate }
\end{array}
\end{array},
\end{aligned}
$$

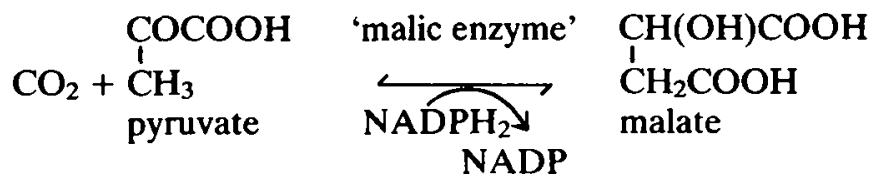

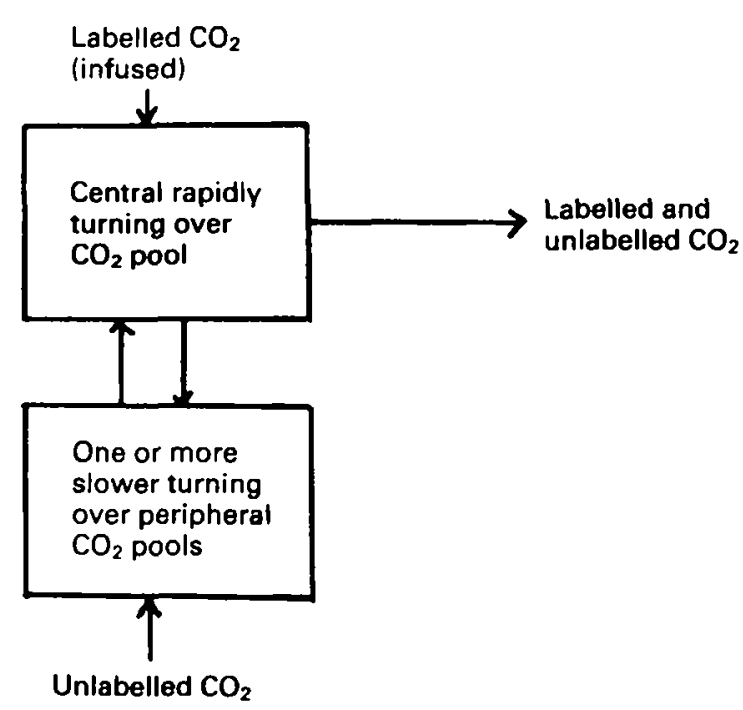

Fig. 2. A two-or-more compartment model of carbon dioxide kinetics. 
These last two reactions form products which are intermediates in the citric acid cycle. Their $\mathrm{C}$ skeleton may be used to form amino acids, lipids and glycogen due to the distribution to ${ }^{13} \mathrm{C}$ or ${ }^{14} \mathrm{C}$ on both of the carboxyl groups of citric acid cycle intermediates (Krebs et al. 1966; Brosnan, 1982), and to the operation of anaplerotic reactions that feed into and out of the citric acid cycle.

Another process that may lead to apparent 'trapping' of $\mathrm{CO}_{2}$ is the entry of $\mathrm{CO}_{2}$ into pools that turn over slowly. Clearly the fractional recovery of ${ }^{13} \mathrm{CO}_{2}$ or ${ }^{14} \mathrm{CO}_{2}$ in expired air is likely to be less complete when the period of collection is short and close to the start of the infusion of labelled $\mathrm{CO}_{2}$. Although the details of bicarbonate kinetics are somewhat controversial (for references, see Irving et al. 1983), it appears that $\mathrm{CO}_{2}$ in the body exists in a central rapidly turning over pool which includes $\mathrm{CO}_{2}$ in the circulation, (free $\mathrm{CO}_{2}$, bicarbonate, carbonic acid and carboxyhaemoglobin), and one or more other pools (e.g. muscle) which turn over more slowly (Fig. 2). The pool of $\mathrm{CO}_{2}$ in bone turns over particularly slowly. Thus although the daily $\mathrm{CO}_{2}$ production in adult man may be fifteen to twenty times greater than the total freely-exchangeable $\mathrm{CO}_{2}$ of the body (0.8-1.0 mol; Allsop et al. 1978; Irving et al. 1983), some of the pools have a turnover of more than fifteen to twenty times per $d$, whilst others a turnover rate of less than fifteen to twenty times per $d$.

The previously-mentioned observations have two important implications for the labelled bicarbonate method for assessing energy expenditure. First, a more appropriate equation than equation 1 for calculating $\mathrm{CO}_{2}$ production is equation 2 .

$$
\mathrm{CO}_{2} \text { production }=\frac{\text { labelled infused } \times f}{\text { specific activity of } \mathrm{CO}_{2}},
$$

where $f$ is the fractional recovery of ${ }^{14} \mathrm{CO}_{2}$ of ${ }^{13} \mathrm{CO}_{2}$ in breath. Second, if the value of $f$ varies considerably, either between individuals or in the same individual at different times, then substantial error will arise in the estimate of $\mathrm{CO}_{2}$ production when a constant value of $f$ is used in equation 2 . Furthermore, since the specific activity of $\mathrm{CO}_{2}$ may vary with time, it is important to measure the specific activity of $\mathrm{CO}_{2}$ over a sufficiently long period of time (e.g. 12-24 h) so that a more representative mean value of specific activity can be used in equation 2.

Animal studies. The labelled bicarbonate method has been used to assess the energy expenditure of free-living animals, (for example, see White \& Leng, 1969; Young \& Corbett, 1969; Young 1970; Corbett et al. 1971). The estimates based on the labelled technique were found generally to agree to within $15-20 \%$ of those obtained by direct measurements of gaseous exchange. The estimate of $\mathrm{CO}_{2}$ production by the tracer technique depends to some extent on the sample that is used for measuring specific activity (e.g. breath, urine or blood; Young, 1970; Corbett et al. 1971). For example, in one study (Corbett et al. 1971) the specific activity of $\mathrm{CO}_{2}$ in breath was found to be about $7 \%$ lower than that in jugular venous blood. This difference was considered to be due to eructation of unlabelled or weakly-labelled $\mathrm{CO}_{2}$ from the rumen into expired air. However, it must also be remembered that the specific activity of $\mathrm{CO}_{2}$ in jugular venous blood is influenced by the $\mathrm{CO}_{2}$ produced locally in the head. Corbett et al. (1971) concluded that the specific activity of $\mathrm{CO}_{2}$ in urine is a more reliable indicator of the overall specific activity of $\mathrm{CO}_{2}$ in the body, partly because urine measurements were considered to reflect mean values over a period of time, and partly because urinary $\mathrm{CO}_{2}$ was considered to be largely derived from arterial blood, rather than from the kidneys. However, when there are no major fluctuations in $\mathrm{CO}_{2}$ production, as in many of the 
sheep studied by Corbett et al. (1971) spot measurements of specific activity in urine, blood or breath may be used to obtain an approximate estimate of energy expenditure.

$\mathrm{CO}_{2}$ entry rates have also been assessed in studies involving a single injection of bicarbonate into the circulation. The results were found to correlate satisfactorily with those obtained by the constant infusion technique (White \& Leng, 1969). However, with the single-injection method it is essential to make frequent measurements of $\mathrm{CO}_{2}$ specific activity and to subject the results to detailed mathematical analysis (White \& Leng, 1969; Irving et al. 1983). This is because there is a rapid multi-exponential loss of label from the central compartment into other $\mathrm{CO}_{2}$ compartments and into breath.

Studies in man. We have recently evaluated the potential value of the constantbicarbonate-infusion technique in six healthy lean male subjects in studies carried out over $36 \mathrm{~h}$ in whole-body indirect calorimeters. During the study breath tests were carried out frequently and the results compared with those obtained from the analysis of 3-hourly urine samples. In addition a portion of the air leaving the calorimeter was dried with calcium chloride, which is free of $\mathrm{CO}_{2}$ adsorption effects (Elia et al. 1986), and passed continuously through a $\mathrm{CO}_{2}$-trapping agent for the duration of study (twelve 3-hourly collections). This unique approach in humans allowed continuous measurements of specific activity to be compared with a series of spot measurements.

The mean recovery of the ${ }^{14} \mathrm{CO}_{2}$ which was trapped continuously between 12 and $36 \mathrm{~h}$ was 95.6 (sD $1 \cdot 1$ ) \%, range $94-97 \%(n 6)$. The variation in recovery was considerably less than that reported in any other study. This implies that if a value for $f$ of 0.95 is used in equation $2, \mathrm{CO}_{2}$ production in our subjects will be predicted to within $2 \%$. It should be noted that the $95 \%$ recovery of ${ }^{14} \mathrm{CO}_{2}$ observed between 12 and $36 \mathrm{~h}$ was greater than that observed earlier between 3 and $8 \mathrm{~h}$ (approximately $85 \%$ ). It was also higher than the mean values obtained in most other human studies $(80-85 \%)$ which involved intermittent spot measurements of breath samples of expired air between 2 and $8 \mathrm{~h}$. The higher recovery in our study was probably due to the prolonged period of collection which allowed sufficient time for labelled $\mathrm{CO}_{2}$ to recycle through slowly turning over pools.

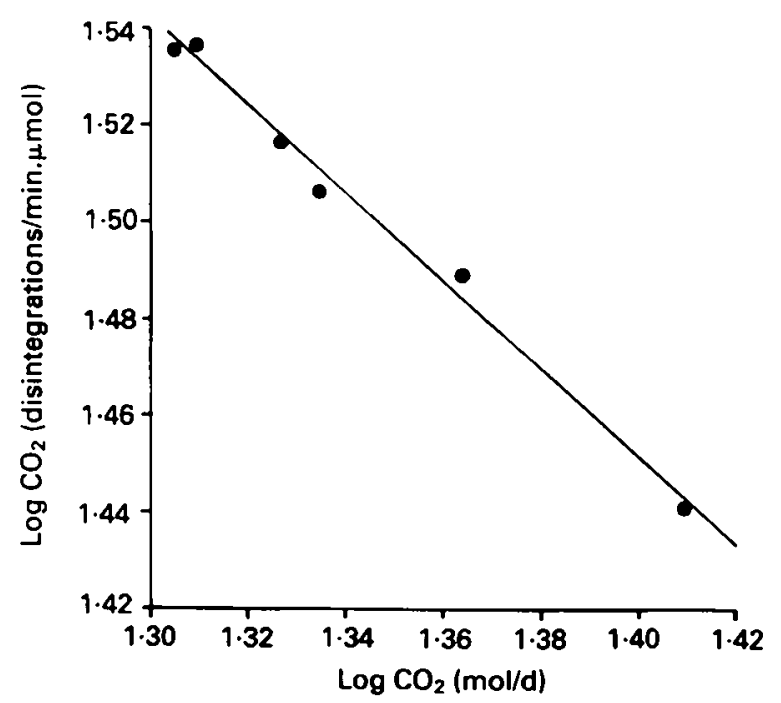

Fig. 3. The relationship between log carbon dioxide production over $24 \mathrm{~h}(12-36 \mathrm{~h})$ and $\log$ specific activity of $\mathrm{CO}_{2}$ (calculated for continuously collected samples) $(r 0.994)$. 

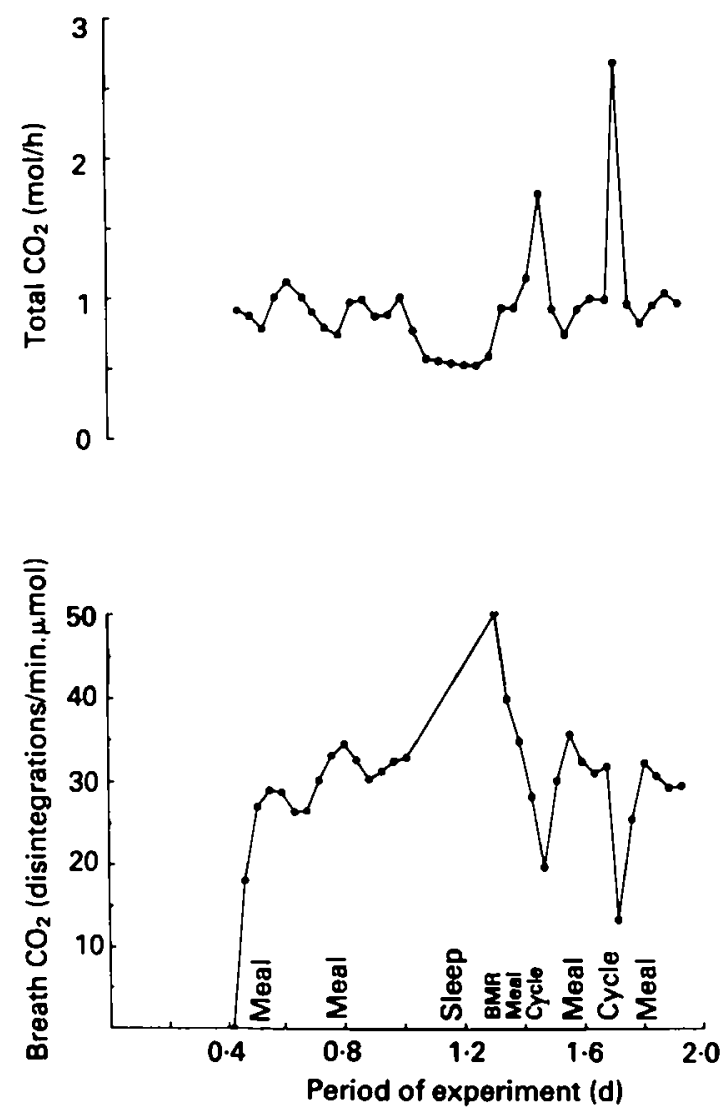

Fig. 4. The change in carbon dioxide production and in specific activity of $\mathrm{CO}_{2}$ in spot breath samples during a $36 \mathrm{~h}$ calorimeter run in one subject.

The only other human study involving a 36-h infusion of bicarbonate concluded, on the basis of spot breath tests, that the mean recovery of labelled $\mathrm{CO}_{2}$ in breath was about 93\% (Clugston \& Garlick, 1983).

Since the recovery of labelled $\mathrm{CO}_{2}$ in our study was remarkably constant over the period 12-36 h, the inverse correlation between $\mathrm{CO}_{2}$ production and $\mathrm{CO}_{2}$ specific activity was also remarkably good $(r-0.994$; Fig. 3 ). However, these mean $24-h$ values give no indication of the short-term changes which occur as a result of sleep, exercise and food ingestion. The short-term changes in the spot breath samples of a typical subject are indicated in Fig. 4. Initially the specific activity of $\mathrm{CO}_{2}$ was low as the label equilibrated with the bicarbonate pools. After $3 \mathrm{~h}$ there were small fluctuations in specific activity and in $\mathrm{CO}_{2}$ production. During sleep $\mathrm{CO}_{2}$ production decreased whilst the specific activity of $\mathrm{CO}_{2}$ increased (Fig. 4). During a 1-h period of mild exercise (1 kp) there was a modest increase in $\mathrm{CO}_{2}$ production and a reciprocal decrease in specific activity. After the exercise period both $\mathrm{CO}_{2}$ specific activity and $\mathrm{CO}_{2}$ production returned towards normal. The changes that occurred during more severe exercise ( $2 \mathrm{kp}$ for $1 \mathrm{~h}$ ) were more marked (Fig. 4). It therefore appears that there is an inverse relationship between $\mathrm{CO}_{2}$ production and $\mathrm{CO}_{2}$ specific activity in breath during periods as short as $1 \mathrm{~h}$. 


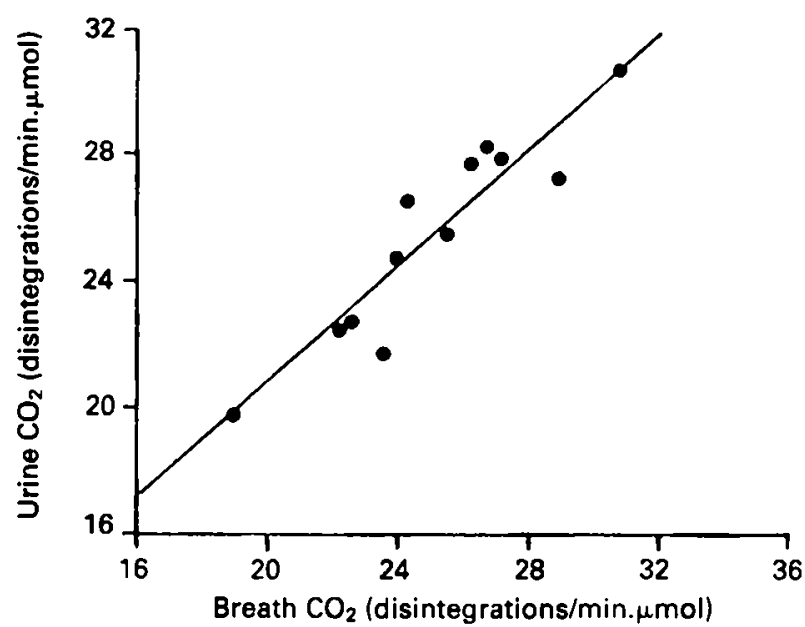

Fig. 5. The relationship between carbon dioxide production and specific activities of $\mathrm{CO}_{2}$ in the urine samples of one subject.
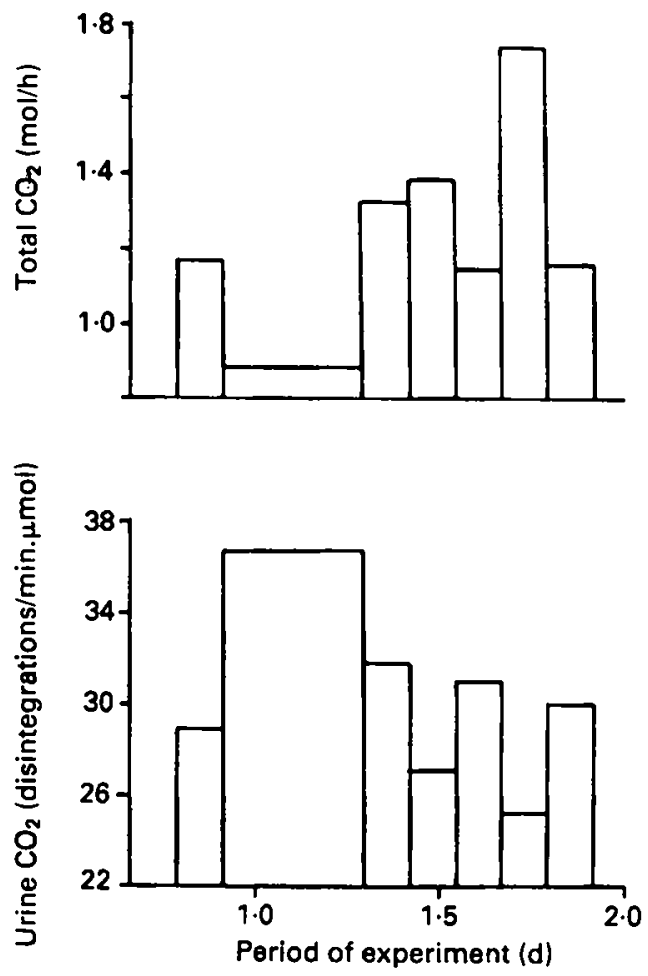

Fig. 6. The relationship between the specific activity of carbon dioxide in urine samples collected over $3 \mathrm{~h}$ and the specific activity in spot breath tests (aggregate values over $3 \mathrm{~h}$ ). The samples were collected during the periods that included $1 \mathrm{~h}$ of cycling. 
The specific activity of $\mathrm{CO}_{2}$ in urine correlated with the specific activity of $\mathrm{CO}_{2}$ in spot breath samples (Fig. 5) and varied inversely with $\mathrm{CO}_{2}$ production (Fig. 6). The composite mean values of specific activity in urine samples collected over $24 \mathrm{~h}$ were 98 (sD 4.5 )\% of those in the expired $\mathrm{CO}_{2}$ which was collected continuously over the same period of time. The composite mean values for spot breath tests were 100 (sD 2)\% of the continuously collected samples. The larger variation in the urine results (SD more than twice that for spot breath samples), may be partly related to the wide variation in the $\mathrm{CO}_{2}$ content of the urine that enters the bladder (see below). Fig. 7 shows the wide variation in the concentration of acid-labile $\mathrm{CO}_{2}$ in samples of urine obtained from a variety of normal subjects. There may also be major fluctuations in $\mathrm{pH}$ and $\mathrm{CO}_{2}$ concentration of urine obtained from the same individual at different times of day (Macy, 1942). For example, meal ingestion in normal subjects may be associated with a rise in urine $\mathrm{pH}$ (Fig. 8) and urinary $\mathrm{CO}_{2}$ concentration (the 'alkaline tide' of feeding). During total starvation urine $\mathrm{pH}$ may decrease to a value between 4.5 and 5 and increase again on refeeding. The diurnal changes in $\mathrm{pH}$ and $\mathrm{CO}_{2}$ concentration in the urine of one of the subjects involved in the bicarbonate tracer study are indicated in Fig. 9.

These variations in urine and $\mathrm{pH}$ and $\mathrm{CO}_{2}$ concentration have important implications for the estimation of mean specific activity in bicarbonate studies. When a urine sample with a high $\mathrm{CO}_{2}$ content mixes with one that has a low $\mathrm{CO}_{2}$ content, the resulting specific activity of $\mathrm{CO}_{2}$ will not be half-way between the two individual specific activities, but

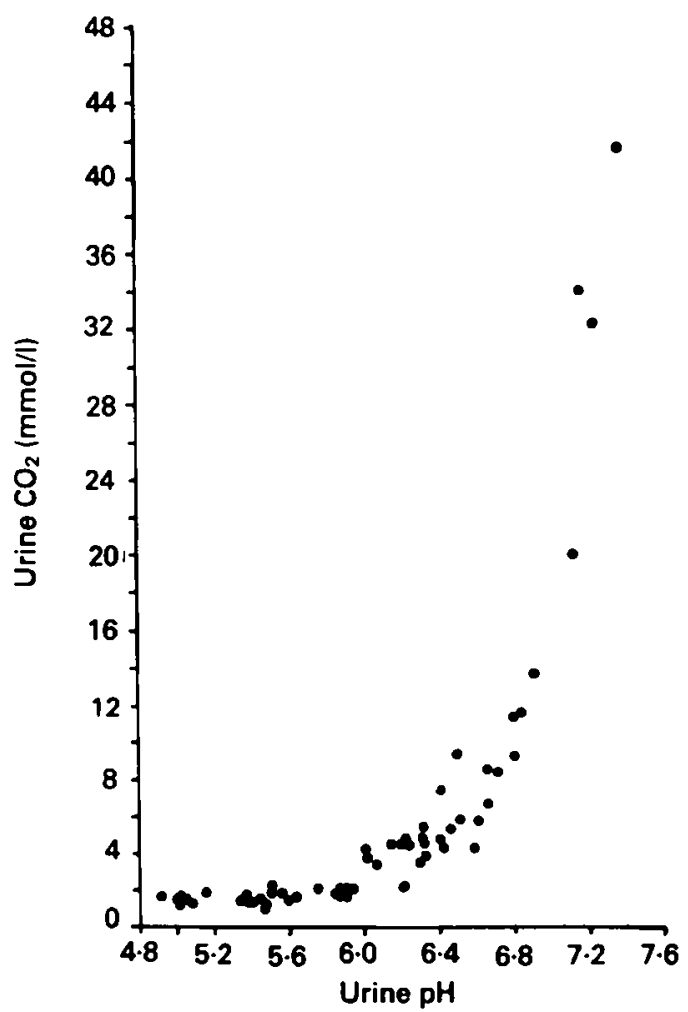

Fig. 7. The relationship between $\mathrm{pH}$ and the concentration of acid-labile carbon dioxide in urine samples obtained from normal subjects. 

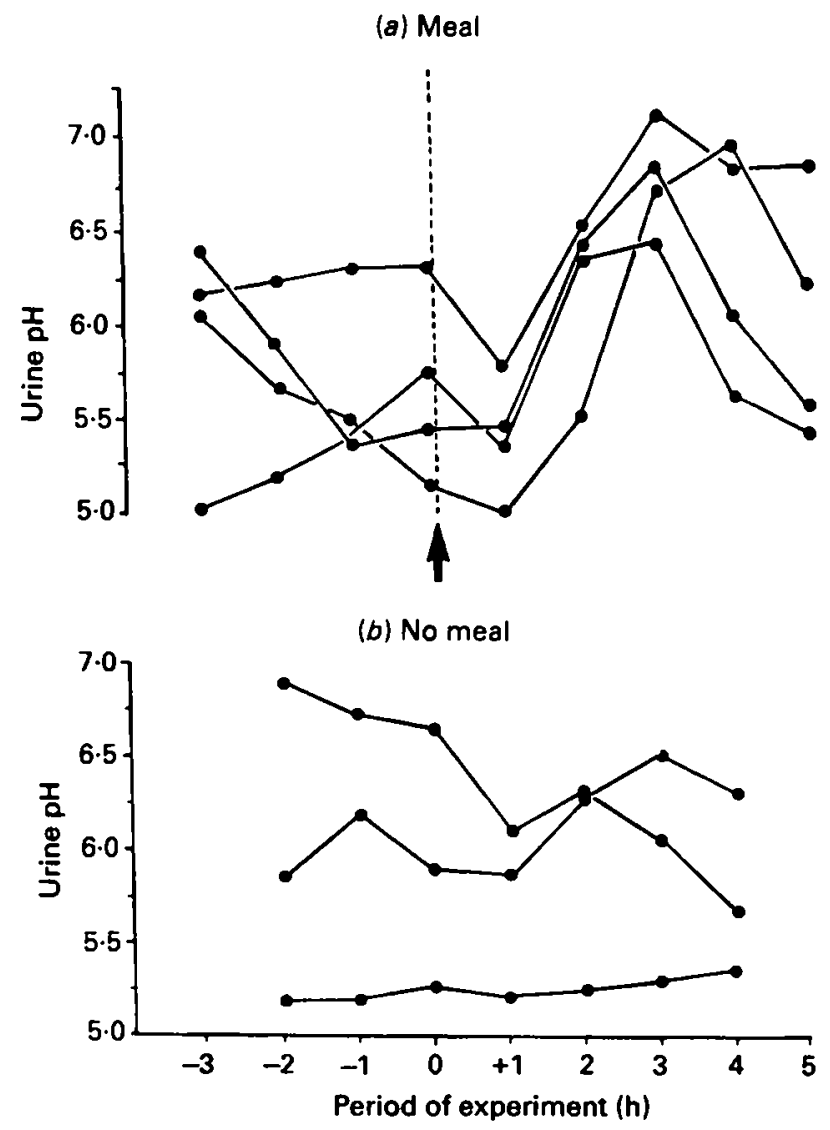

Fig. 8. The effect of a single meal $(\uparrow)$ on urine pH (a). The meal, which consisted of $3724 \mathrm{~kJ}(890 \mathrm{kcal})$ was taken at 12.30 hours following an overnight fast. The control subjects missed breakfast as well as the midday meal (b).

heavily displaced towards the one with the high $\mathrm{CO}_{2}$ content. Such an effect may also occur when urine produced by the kidney mixes with urine already in the bladder.

A second problem that may arise during storage of urine in the bladder, is the exchange of labelled $\mathrm{CO}_{2}$ with blood $\mathrm{CO}_{2}$. If such an exchange occurred rapidly and completely, urine specific activity would be equivalent to that of a spot blood or breath test. If no exchange of label occurred, the specific activity of urinary $\mathrm{CO}_{2}$ would depend on the total labelled and unlabelled $\mathrm{CO}_{2}$ excreted by the kidney over a period of time. The truth almost certainly lies somewhere between these two extremes. In studies involving direct instillation of labelled bicarbonate (together with a marker for assessing urine volume) into the bladders of catheterized post-operative patients, it was found that a substantial transfer of $\mathrm{CO}_{2}$ occurred through the bladder wall (up to $30-40 \%$ every 0.5 h). The label entered the circulation and was subsequently detected in breath. The fractional transfer of labelled $\mathrm{CO}_{2}$ across the bladder was found to depend on both the concentration of acid-labile $\mathrm{CO}_{2}$ in urine ( $\mathrm{pH}$ related) and on the volume of urine in the bladder (M. Elia and N. Fuller, unpublished results). Presumably the transfer of $\mathrm{CO}_{2}$ across the bladder is bi-directional so that the net change in urine specific activity will 

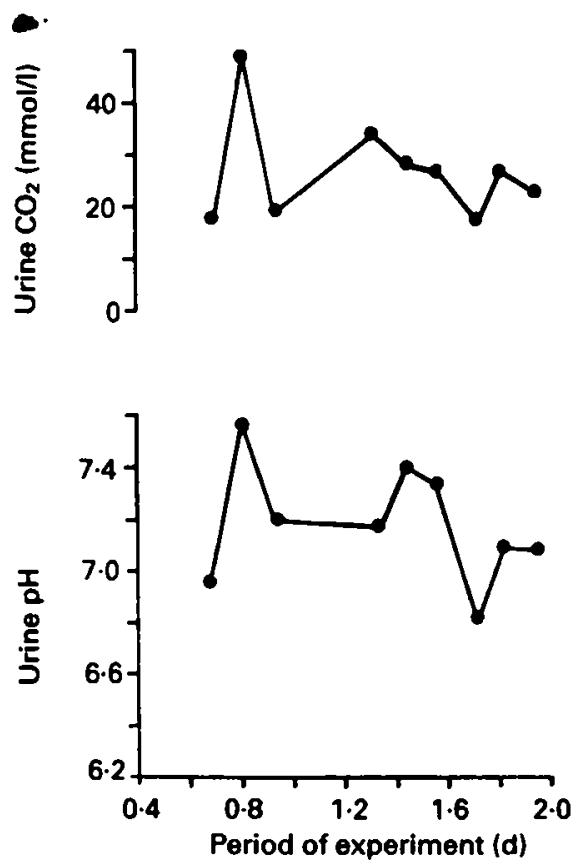

Fig. 9. The daily variation (12-36h) in urine $\mathrm{pH}(3 \mathrm{~h}$ urine samples) in a subject participating in a bicarbonate-infusion study. A constant low-dose infusion of sodium bicarbonate was given between 0 and $36 \mathrm{~h}$.

depend on the differences in specific activity between blood and urine. If no such difference exists, no change in specific activity will occur. If there is a difference, the two compartments would tend to equilibrate. In practice many of the above effects may cancel out, particularly in studies carried out over long periods of time, e.g. $24 \mathrm{~h}$.

The energy equivalent of $\mathrm{CO}_{2}$

Once the estimated $\mathrm{CO}_{2}$ production is established, it is necessary to relate it to energy expenditure. Unfortunately the energy equivalent of $\mathrm{CO}_{2}$ is not constant since it depends on the type of fuels being oxidized. When a glucose polysaccharide is oxidized the following equation applies (Elia \& Livesey, 1988):

$$
n\left[\mathrm{C}_{6} \mathrm{H}_{10} \mathrm{O}_{5}\right] n+n 6 \mathrm{O}_{2} \longrightarrow n 6 \mathrm{CO}_{2}+n 5 \mathrm{H}_{2} \mathrm{O} ;-\mathrm{H}=2840 \mathrm{~kJ} / \mathrm{n} \text {. }
$$

The respiratory quotient is 1 and the energy equivalent of $\mathrm{CO}_{2}$ is $21 \cdot 12 \mathrm{~kJ} /(473.3 \mathrm{~kJ} / \mathrm{mol}$ $\mathrm{CO}_{2}$. When the triglyceride dioleylpalmityl triglyceride is oxidised, the following equation applies (Elia \& Livesey, 1988):

$$
\mathrm{C}_{55} \mathrm{H}_{102} \mathrm{O}_{6}+77 \cdot 5 \mathrm{O}_{2} \longrightarrow 55 \mathrm{CO}_{2}+51 \mathrm{H}_{2} \mathrm{O} ;-\mathrm{H}=33876 \mathrm{~kJ} / \mathrm{mol} \text {. }
$$

The respiratory quotient (RQ) is 0.7097 and the heat equivalent of $\mathrm{CO}_{2}$ is $27.48 \mathrm{~kJ} / \mathrm{h}$ $\mathrm{CO}_{2}$ or $615.9 \mathrm{~kJ} / \mathrm{mol} \mathrm{CO}$. These values are $30 \%$ higher than that for polysaccharide oxidation. The energy equivalents of $\mathrm{CO}_{2}$ production rates over a range of non-protein $R Q$ values, including those above 1, which are associated with net lipid synthesis, are illustrated in Table 1. It is clear that the variation in the non-protein-energy equivalent of $\mathrm{CO}_{2}$ is greater than the variation in energy equivalents of $\mathrm{O}_{2}$. Protein oxidation usually 
Table 1. The non-protein energy equivalent of oxygen and carbon dioxide (values from Elia \& Livesey, 1988)

\begin{tabular}{ccc}
$\begin{array}{c}\text { Non-protein } \\
\text { respiratory } \\
\text { quotient }\end{array}$ & \multicolumn{2}{c}{$\begin{array}{c}\text { Heat equivalent } \\
(\mathrm{kJ} / \mathrm{l})\end{array}$} \\
0.7097 & $\mathrm{O}_{2}$ & $\mathrm{CO}_{2}$ \\
0.75 & 19.50 & 27.48 \\
0.80 & 19.73 & 26.30 \\
0.85 & 20.00 & 25.00 \\
0.90 & 20.28 & 23.86 \\
0.95 & 20.56 & 22.87 \\
1.00 & 20.84 & 21.94 \\
1.05 & 21.12 & 21.12 \\
1.10 & 21.40 & 20.38 \\
& 21.68 & 19.71
\end{tabular}

makes little difference to the overall energy equivalents of $\mathrm{CO}_{2}$, partly because protein oxidation accounts for only a small proportion of total energy expenditure (about $15 \%$ ) and partly because the value for the energy equivalent of $\mathrm{CO}_{2}$ for protein oxidation is intermediate between that for fat and carbohydrate oxidation (Livesey \& Elia, 1988).

In subjects who are in energy balance over long periods of time, the mean RQ should be close or equal to the food quotient (i.e. the RQ associated with the oxidation of dietary constituents). The food quotient of Western societies and of individual subjects in these societies is about $\mathbf{0 . 8 5}$. The value is often higher in Third World countries where the diet contains a large proportion of carbohydrate. It may, however, vary considerably in subjects who are not in energy balance. For example, during starvation the RQ may be close to 0.70 (Elia et al. 1984, 1987) whereas in hospitalized patients receiving a hyperenergetic parenteral nutrition regimen with glucose as the main energy fuel, the RQ may be 1 or more. Furthermore, there may be variation in the RQ of the same subject at different times of the day, e.g. a meal containing $3350 \mathrm{~kJ}$ (800 kcal) may increase the RQ by $0.05-0.010$, whilst prolonged exercise may be associated with a progressive reduction of $\mathrm{RQ}$ as glycogen stores become depleted and fat is used increasingly as an energy source. The variation in the respiratory exchange ratio of a typical subject participating in a 36-h calorimetry study is indicated in Fig. 10. The lowest values were observed during sleep and the highest after meal ingestion and during exercise. In the bicarbonate method it is necessary to estimate the mean $R Q$ which is likely to prevail over the period of study so that an appropriate value for energy expenditure can be calculated (Table 1). If a value for $R Q$ of 0.85 is chosen to calculate energy expenditure in conjunction with the $24 \mathrm{~h}$ measurements of specific activity in urine and spot breath samples, the results are $100 \cdot 8$ (sD 5.9) \% (range 92-107\%) and 98.4 (SD 2.9 ) \% (range $94-101 \%$ ) respectively of those calculated from gaseous exchange.

\section{Some practical considerations}

A disadvantage of the bicarbonate method is that the labelled compound cannot be given orally because of acidity in the stomach which may release gaseous $\mathrm{CO}_{2}$. This $\mathrm{CO}_{2}$ may be eructated without entering the central bicarbonate pool. Therefore the labelled compound has to be given intravenously or subcutaneously (or intraperitoneally, as in some animal studies). Although intravenous administration of bicarbonate is not a major difficulty in hospitalized patients, particularly those that are already receiving an intravenous infusion, in free-living subjects it can pose major difficulties. However, a 


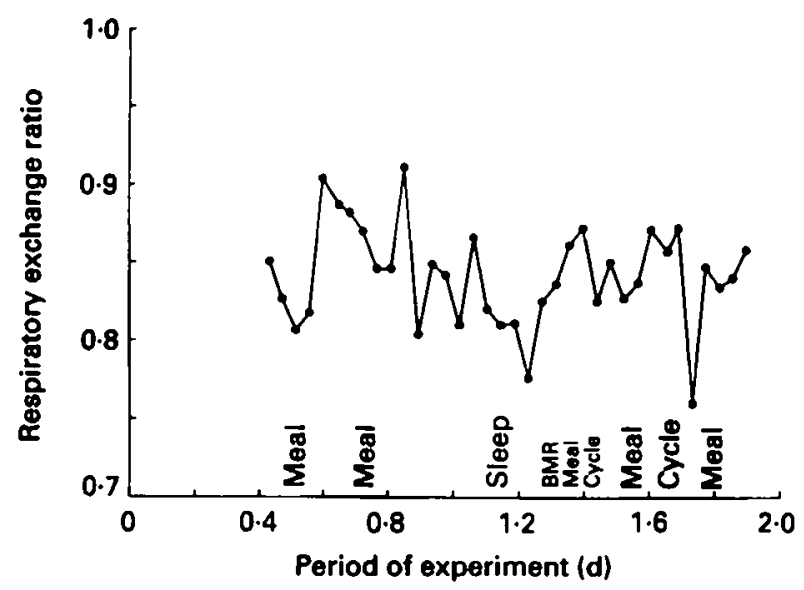

Fig. 10. The change in the respiratory exchange ratio in a subject participating in a bicarbonate-infusion study.

continuous subcutaneous infusion of labelled bicarbonate via a mini pump is feasible since many diabetics use this method for administering insulin to control their blood sugar concentration over 24 -h periods.

A second practical consideration concerns sampling. Spot breath, blood, or salivary samples may have to be taken frequently during periods of altered activity, in order to ensure that important changes in $\mathrm{CO}_{2}$-specific activity are not overlooked. The sampling procedure may therefore interfere with the normal pattern of daily activities. Urine samples can be more conveniently used for assessing mean specific activities over a period of time but the results in normal subjects may be only approximate for reasons already discussed. A further error may be introduced, especially in short-term studies, because the energy equivalent of $\mathrm{CO}_{2}$ (Elia \& Livesey, 1988) has to be predicted. Nevertheless, in normal subjects, energy expenditure during 24-h periods could be predictable to within about $10 \%$.

\section{REFERENCES}

Allsop, J. R., Wolfe, R. R. \& Burke, J. F. (1978). Journal of Applied Physiology 45, 137-139.

Brosnan, J. T. (1982). Federation Proceedings 41, 91-95.

Clugston, G. A. \& Garlick, P. J. (1983). Clincal Science 64, 231-233.

Corbett, J. L., Farrell, D. J., Leng, R. A., McClymont, G. L. \& Young, B. A. (1971). British Journal of Nutrition 26, 277-291.

Coward, W. A. (1988). Proceedings of the Nutrition Society 47, $209-218$.

Elia, M., Lammert, O., Zed, C. \& Neale, G. (1984). Human Nutrition: Clinical Nutrition 38C, 355-362.

Elia, M. \& Livesey, G. (1988). American Journal of Clinical Nutrition 47, 591-607.

Elia, M. McDonald, T. \& Crisp, A. (1986). Clinica Chimica Acta 158, 237-244.

Elia, M., Zed, C., Neale, G. \& Livesey, G. (1987). Metabolism 36, 251-255.

Irving, C., Wong, W. W., Shulman, R. J., Smith, E. O'B. \& Klein, P. D. (1983). American Journal of Physiology 245, R190-R202.

Issekutz, B., Paul, P., Miller, H. I. \& Bortz, W. M. (1968). Metabolism 17, 63-73.

James, W. P. T., Garlick, P. M., Sender, P. M. \& Waterlow, J. C. (1976). Clinical Science 50, 525-532.

Krebs, H. A., Hems, R., Weidemann, M. J. \& Speake, R. N. (1966). Biochemical Journal 101, 243-249.

Lifson, N., Gordon, G. B. \& McClintock, R. (1955). Joumal of Applied Physiology 7, 704-710.

Livesey, G. \& Elia, M. (1988). American Joumal of Clinical Nutrition 47, 608-628. 
Macy, I. G. (1942). Nutrition and Chemical Growth in Childhood, vol. 1, pp. 115-117. Springfield, Illinois and Baltimore, Maryland: Charles C. Thomas.

Prentice, A. M. (1988). Proceedings of the Nutrition Society 47, 259-268.

White, R. G. \& Leng, R. A. (1969). Proceedings of the Australian Society of Animal Production 7, $335-341$.

Winchell, H. S., Stahelin, H., Kusubor, N., Slanger, B., Fish, M., Pollycove, M. \& Lawreno, J. H. (1970). Journal of Nuclear Medicine 11, 711-715.

Young, B. A. (1970). In Energy Metabolism of Farm Animals, European Association for Animal Production Publication no 13, pp. 237-241 [A. Schürch and C. Wenk, editors]. Zurich: Juris Druck + Verlag.

Young, B. A. \& Corbett, J. L. (1969). Proceedings of the Australian Society of Animal Production 7, 327-336. 